\title{
PKU BAGI MI MUHAMMADIYAH MEDURO MELALUI MAJALAH DINDING MENGASAH KREATIVITAS MENULIS DAN GEMAR MEMBACA SISWA
}

\author{
Minzani Aufa (), Norma Dewi Shalikhah 2), Ayu Faiza Algifahmy ${ }^{3)}$ \\ ${ }^{1)}$ Fakultas Agama Islam Universitas Muhamadiyah Magelang \\ Email: minzaniaufa@ummgl.ac.id \\ 2) Fakultas Agama Islam Universitas Muhamadiyah Magelang \\ Email: normadewi@ummgl.ac.id \\ 3) Fakultas Agama Islam Universitas Muhamadiyah Magelang \\ Email: ayufaiza@ummgl.ac.id
}

\begin{abstract}
ABTRACT
The problem faced by the Madrasah Ibtidaiyah Muhammadiyah Meduro in Magelang Regency is the low level of understanding of knowledge about Wall Magazine in Meduro MI, lack of maximizing existing facilities and infrastructure, teachers not motivating students to write in madding, lack of reading and writing interest from students. The purpose of this service includes two things, namely: 1. The long term consists of a. Provide a place for students to develop creations, especially in the field of writing and reading. $b$. Instil a soul like reading and writing early. 2 . The specific target to be achieved through this service is that students can make interesting mading. To achieve this goal, carried out using the method of Participatory Rural Appraisal (PRA). The PRA method is chosen based on the consideration that those who have or face a problem our partners, therefore the involvement of partners in determining problem-solving and resolution is essential. The method is divided into three stages, namely, preparation, implementation, and preparation of reports.
\end{abstract}

Keywords: Wall Magazine, Reading and Writing, Madrasah Ibtidaiyah

\section{PENDAHULUAN}

Meningkatkan mutu dan kualitas siswa MI adalah menjadi kebutuhan yang harus dilakukan, yaitu dengan pemberdayaan siswa secara optimal. Pada dasarnya banyak diantara siswa yang memiliki potensi untuk menulis, hanya saja potensi yang dimiliki belum terasah karena tidak ada upaya untuk meningkatkan keterampilan mereka dan tidak ada media sebagai tempat untuk menyalurkan ide-ide, gagasan dan kreativitasnya. Majalah dinding (mading) adalah salah satu jenis media komunikasi massa tulis yang paling sederhana. Majalah dinding (Mading, atau Koran Dinding, Kording) paling murah dan sederhana sebagai media sekolah. Modalnya cuma papan board atau tembok berukuran standard ( $2 \mathrm{~m} \times 1,5 \mathrm{~m})$, atau lebih kecil, lalu tempelan kertas gambar atau manila polos atau berwarna (Muntaha, 2009:35).

Melalui Permendikbud No. 23 Tahun 2015, sekolah kini diwajibkan menggalakkan budaya literasi.Lebih spesifiknya mewajibkan warga sekolah membaca selama 15 menit, tiap hari. Jadi bukan hanya siswa, tapi guru, kepala sekolah, staff, bahkan penjaga. Majalah dinding sebagai pendorong siswa untuk membaca, menilai dan menanggapi. Jadi, majalah dinding dapat meningkatkan keinginan siswa untuk membaca, setidaknya membaca isi majalah dinding pada setiap edisinya. Ketertarikan ini tentu dipancing dengan penampilan majalah dinding yang baru dan menarik di setiap edisinya. Melalui 
membaca, mereka akan mengetahui dan dapat mengembangkan kemampuannya dalam jurnalistik. Sehingga pada akhirnya, mereka dapat menilai dan mengomentari tulisan yang dipajang pada majalah dinding. (Ayu Mayendri, 2013:9).

Membaca-menulis (literasi) merupakan salah satu aktifitas penting dalam hidup. Sebagian besar proses pendidikan bergantung pada kemampuan dan kesadaran literasi. Budaya literasi yang tertanam dalam diri peserta didik mempengaruhi tingkat keberhasilan baik di sekolah maupun dalam kehidupan bermasyarakat. Menulis dapat membuat pikiran kita lebih tertata tentang topik yang kita tulis, membuat kita bisa merumuskan keadaan diri, mengiat dan menggkonstruksi gagasan, mengefektifkan atau membuat kita memiliki sugesti (keyanikanan / pengaruh) positif, membuat kita semakin pandai memahami sesuatu (menajamkan pemahaman), meningkatkan daya ingat, membuat kita lebih mengenali diri kita, mengalirkan diri, membuang kotoran diri, merekam momen mengesankan yang kita alami, meninggalkam jejak pikiran yang sangat jelas, memfasihkan komunikasi, memperbanyak kosa kata, membantu bekerjanya imajinasi dan menyebarkan pengetahuan.

Majalah dinding dapat memberikan inspirasi bagi para siswa untuk dapat menuangkan gagasan, ide dan kreativitasnya dalam bentuk tulisan. Melalui majalah dinding, siswa dapat mengembangkan potensi menulisnya sehingga menjadi semakin baik dan berkualitas. Untuk dapat mencapai hal tersebut perlu adanya dorongan dari guru untuk terus memotivasi para siswa agar terus mengembangkan potensinya dalam hal menulis dan bila perlu dengan memberi tugas-tugas terstruktur (Hari Santoso, 2007:7). Dalam konteks pendidikan nasional kita, minat baca-tulis masyarakat kita sangar mengkhawatirkan, hal ini disebablan adanya berbagai persoalan, karena kegiatan menulis memerlukan banyak waktu, tenaga, pikiran serta perhatian yang sungguh-sungguh dan juga menuntut keterampilan yang tidak dimiliki semua orang. Kondisi yang demikian perlu adanya upaya untuk meningkatkan kemampuan menulis bagi siswa dan sekaligus membangun budaya membaca, salah satu cara untuk mewujudkan hal tersebut dengan menerbitkan majalah dinding sebagai alat bantu pengajaran dan pembinaan yang diharapkan dapat merangsang kreativitas siswa di Madrasah.

Saat ini, MI Muhammadiyah Meduro sudah memiliki Mading, akan tetapi pemanfaatannya belum makismal sehingga perlu adanya dorongan positif untuk mengembangkan serta memberikan pembekalan kepada siswa supaya rajin dalam membaca dan menulis. Pada dasarnya bahwa majalah dinding dapat menjadi media atau sarana berlatih yang menarik sesuai dengan perkembangan anak didik untuk membina kreativitas menulis dan modal penanaman gemar membaca kepada siswa. Mereka tergolong masih cukupdini apabila tidak diberikan pendampingan secara sungguhsungguh dan berkelanjutan, utamanya dalam membina kreativitas menulis dan gemar membaca siswa di madrasah.

Adanya media majalah dinding, anak usia sekolah dasar akan dirangsang untuk mulai tertarik dengan budaya literasi yang sudah dicanangkan oleh pemerintah. Karena hal ini menekankan pada gaya belajar anak didik, berkaitan dengan gaya visual yang ada.

Dari analisis situasi di atas dapat kita tarik kesimpulan bahwa membaca merupakan suatu hal yang sangat penting dalam meningkatkan pengetahuan dan wawasan siswa. Ide, gagasan dan kreatifitas akan muncul seiring dengan bertambahnya minat baca - tulis mereka. Namun dalam pelaksanaanya muncul permasalahan yang dialami oleh mitra. Berikut disampaikan beberapa hal yang dikeluhkan oleh mitra, antara lain: 1) Rendahnya pemahaman pengetahuan tentang Majalah Dinding di MI Meduro Kabupaten Magelang, 2) Kurang memaksimalkan fasilitas sarana dan prasarana yang ada, 3) Guru kurang memotivasi siswa menulis dalam mading, 4) Kurangnya minat baca dan tulis dari siswa 
Ada dua tujuan yang akan dicapai dalam pelaksanaan pengabdian ini Tujuan Jangka Panjang : 1) Memberikan wadah bagi siswa untuk mengembangkan kreasi khususnya dalam bidang menulis dan membaca. 2) Menanamkan jiwa gemar membaca dan menulis sejak dini. Target khusus yang ingin dicapai melalui pengabdian ini adalah siswa dapat membuat mading yang menarik.

\section{METODE PELAKSANAAN}

Metode yang akan dipakai dalam kegiatan ini adalah model pemberdayaan masyarakat partisipatif yaitu Participatory Rural Apraisal (PRA). Metode PRA dipilih berdasarkan pertimbangan bahwa yang mempunyai atau menghadapi masalah adalah mitra, oleh karena itu keterlibatan mitra dalam penentuan pemecahan masalah dan penyelesaiannya sangat diperlukan. Metode tersebut dibagi menjadi 3 tahap yaitu persiapan, pelaksanaan, dan penyusunan laporan. Rinciannya sebagai berikut: 1 . Tahap persiapan meliputi : menyampaikan ijin kepada Kepala Madrasah karena akan digunakan sebagailokasi kegiatan pengabdian pada masyarakat ini, Menyiapkan teknologi yang akan diterapkan kepada sasaran mitra. menyusun jadwal kegiatan dan melakukan pembagian tugas di antara anggota tim sebagaimana berdasarkan kompetensi masing-masing. 2. Tahap pelaksanaan meliputi: sosialisasi tentang pentingnya menulis dan membaca kepada peserta didik di MIM Meduro Mungkid Kabupaten Magelang, pelatihan pengembangan majalah dinding yang berkualitas dan menarik di MIM Meduro Mungkid Kabupaten Magelang. 3. Tahap pelaksanaan meliputi: praktek pembuatan majalah dinding di MIM Meduro Mungkid Kabupaten Magelang, pendampingan dalam pembuatan majalah dinding. 4. tahap penyusunan laporan, meliputi: penyusunan laporan kemajuan, minimal $75 \%$ selesai dalam waktu sesuai dengan jadwal yang telah ditentukan

Penyusunan laporan akhir beserta seluruh instrument pelaporan dilakukan setelah seluruh kegiatan pengabdian pada masyarakat ini selesai.

\section{HASIL DAN LUARAN YANG DICAPAI}

1. Potensi sosial dan ekonomi Program pengabadian kepada masyarakat dengan tema pendampingan dan pengembangan mutu madrasah memberikan dampak positif dari sisi sosial yaitu stakeholder akan lebih mempercayakan peserta didik dibawah pengajaran dan pembelajaran oleh MI Muhammadiyah Meduro dengan sistem pendampingan oleh Tim Pengembangan Mutu Madrasah sehingga menghasilkan outcomes/lulusan yang unggul. Dari sisi ekonomi akan ada peningkatan sumber pendapatan dimana para guru madrasah akan terangkat kesejahteraanya sesuai dengan usaha dan semangat dalam meningkatkan kualitas dan kuantitas mutu madrasah.

2. Nilai tambah dari sisi IPTEKS

Salah satu program pendampingan pengembnagn mutu madrasah adalah peningkatan kualitas SDM dengan Pelatihan pengembangan metode pembelajaran bagi guru dengan tujuan meningkatkan keterampilan guru dalam mengimplementasikan metode pembelajaran yang lebih aktif, kreatif dan inovatif melalui praktik pembuatan media pembelajaran. Hal ini untuk mengatasi keadaan guru kelas yang tidak memiliki latar belakang pendidikan yang linier sebagai guru kelas. Guru diharapkan dapat menguasai 3 sampai 5 metode pembelajaran yang aktif, kreatif dan inovatif.

3. Dampak manfaat

Lembaga Pendidikan Dasar seperti Madrasah Ibtidaiyah (MI) adalah awal dari sebuah proses pencapaian keberhasilan guna mengenal jati diri siswa untuk meraih mimpi menjadi manusia cerdas dan bermutu dari sisi kognitif, afektif, dan psikomotoriknya. 
Untuk mencapai itu semua maka perlu dilakukan kajian yang lebih mendalam tentang ketercapaian implementasi pemahaman Standar Nasional Pendidikan khususnya pendidikan dasar (MI) untuk menuju madasah unggul dan kompetetif sebagai sumber inti untuk menghasilkan lulusan yang berkualitas.

4. Nilai tambah bagi Universitas Muhamadiyah Magelang (UMMagelang)

Adanya program pendampingan pengembangan mutu madrasah maka akan tercipta program jaringan madrasah Lab-School, yang merupakan salah satu program unggulan di Program Studi Pendidikan Guru Madrasah Ibtidaiyah Fakultas Agama Islam (Prodi PGMI FAI UMMagelang) yang dilaksanakan setiap semester dengan pembentukan Tim Pengembangan Mutu Madrasah.

Kegiatan awal yang dilakukan adalah, melakukan koordinasi dengan pihak MI Muhammadiyah Meduro Kabupaten Magelang, dengan membawa surat tugas program kemitraan universitas melalui program pengabdian guna melakukan persamaan persepsi tentang manajemen peserta didik berupa pendampingan melalui mading, dengan cara menulis dan gemar membaca. Pada pelaksanaannya sesuai metode yang kami gunakan dalam program kemitraan ini adalah Participatory Rural Apraisal (PRA). Metode PRA dipilih berdasarkan pertimbangan bahwa yang mempunyai atau menghadapi masalah adalah mitra, oleh karena itu keterlibatan mitra dalam penentuan pemecahan masalah dan penyelesaiannya sangat diperlukan.

\section{Sosialisasi dan Pelatihan Pembuatan Mading di MIM Meduro Kabupaten Magelang}

Pelaksanaan sosialisasi tentang pentingnya menulis dan membaca diberikan kepada siswa kelas 4 dan 5 MIM Meduro. Siswa diberi motivasi untuk dapat menulis dengan mudah dan gemar membaca dengan harapan dapat membuat pikiran lebih tertata tentang topik yang akan tu- lis, dapat merumuskan keadaan diri, mengkonstruksi gagasan, mengefektifkan atau membuat siswa memiliki sugesti (keyanikanan / pengaruh) positif, membuat semakin pandai memahami sesuatu (menajamkan pemahaman), meningkatkan daya ingat, membuat lebih mengenali diri sendiri, mengalirkan diri, membuang kotoran diri, merekam momen mengesankan yang dialami, meninggalkam jejak pikiran yang sangat jelas, memfasihkan komunikasi, memperbanyak kosa kata, membantu bekerjanya imajinasi dan menyebarkan pengetahuan siswa. Berikut gambar pelaksanaan sosialisasi pentingnya menulis dan membaca pada gambar 1 .

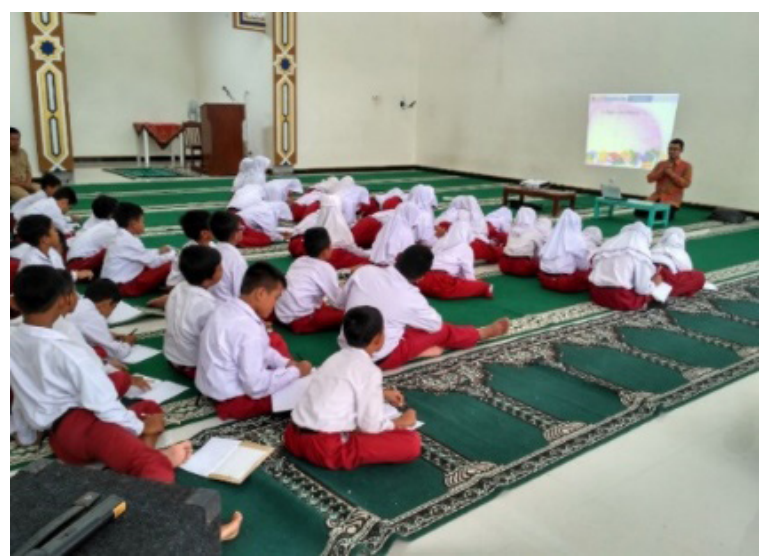

Gambar 1. Sosialisasi pentingnya menulis dan membaca

Setelah siswa mendapatkan motivasi tentang menulis dan membaca, kami memberikan pelatihan pengembangan majalah dinding yang berkualitas dan menarik. Kegiatan ini memberikan pengetahuan kepada siswa tentang cara membuat mading yang menarik, membuat isi mading yang berkualitas, apa saja isi dari mading, dan bahan sederhana apa saja yang digunakan agar tampilan mading menjadi menarik. Dalam pelatihan ini, siswa dibagi menjadi 13 kelompok yang masing-masing kelompok mendapatkan tugas dari isi mading yang pada nantinya akan dibuat mading saat praktek membuat mading dilaksanakan. Setiap kelompok, kami berikan satu paket peralatan mading seperti alat tulis, spidol warna, dan kertas berwarna. Berikut gambar pelatihan pengembangan majalah dinding yang berkualitas dan menarik pada gambar 2 . 


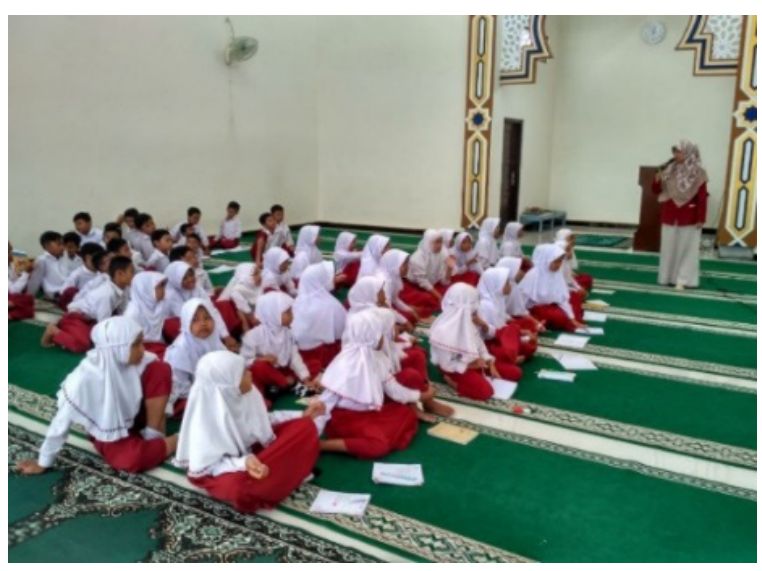

Gambar 2. Pelatihan Pengembangan Mading

Praktik dan pendampingan pembuatan mading di MIM Meduro Kabupaten Magelang

Kegiatanselanjutnyaadalah siswapraktik membuat mading. Kami mendampingi para siswa untuk menuangkan ide siswa ke sebuah tulisan kemudian menuliskannya dalam kertas warna-warni dan didesain semenarik mungkin. Siswa berkelompok sesuai dengan pembagian tugasnya. Berikut gambar praktik dan pendampingan pembuatan mading pada gambar 3.

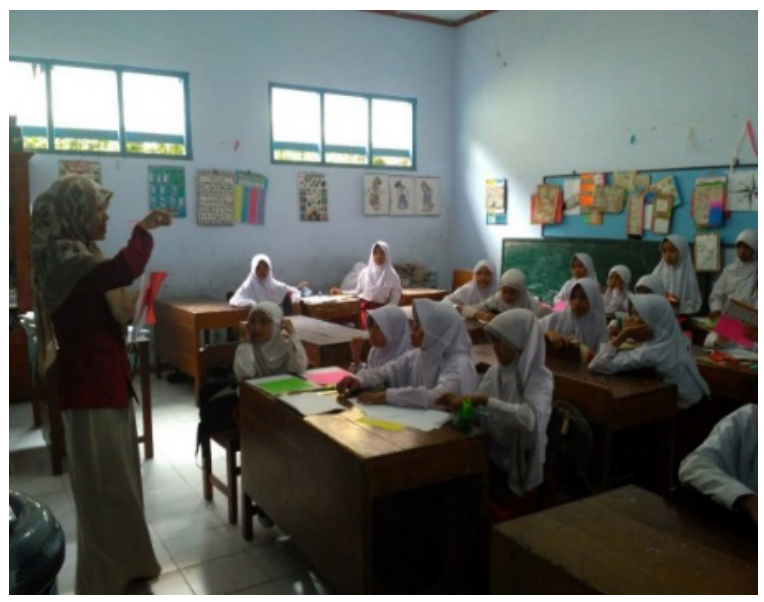

Gambar 3. Praktik dan pendampingan pembuatan mading

Kegiatan selanjutnya penempelan mading yang telah selesai dibuat siswa. Dalam kegiatan penempelan mading, siswa didampingi oleh mahasiswa. Kami memberikan fasilitas media papan mading agar karya mading dari siswa aman dan nyaman ketika dibaca. Berikut penampakkan mading yang telah dibuat oleh siswa pada gambar 4.

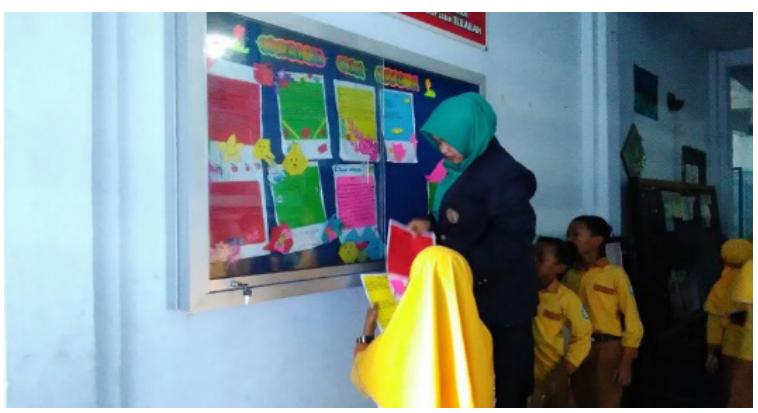

Gambar 4. Penampakkan mading

Berikut ini adalah dokumentasi hasil dari pengabdian di MI Muahmmadiyah Meduro Kabupaten Magelang pada gambar 5.

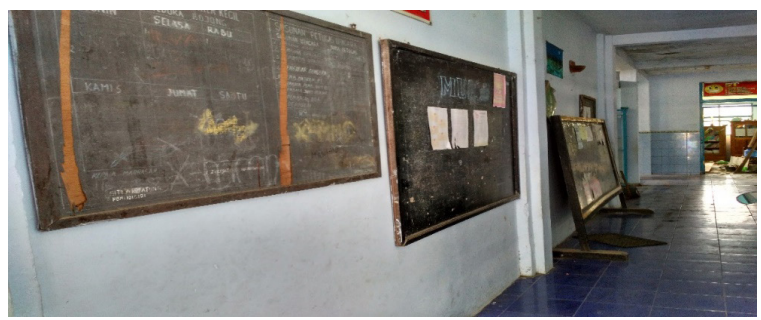

Gambar 5. Mading sebelum pengabdian

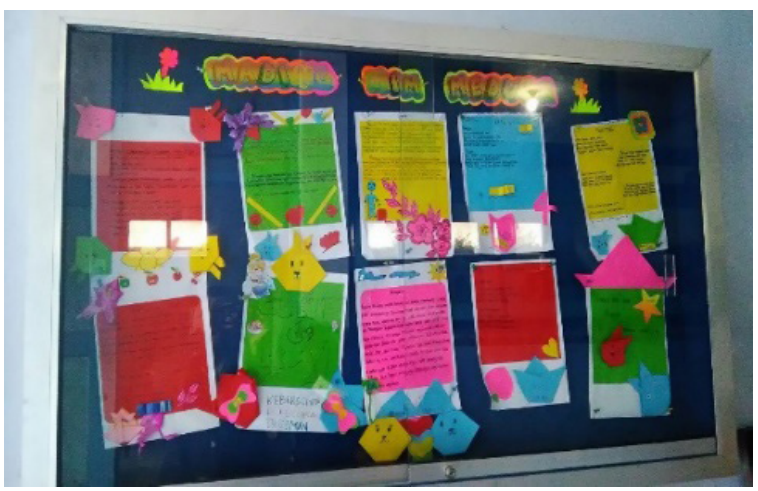

Gambar 6. Mading setelah pengabdian

\section{KESIMPULAN}

Adapun hasil dari Program Kemitraan Universitas dengan judul PKU bagi MI Muhammadiyah Maduro melalui Majalah Dinding Melatih Kreativitas Membaca dan Gemar Menulis Siswa. bahwa pemahaman mading masih terlalu rendah sehingga diperlukan pendamping berkelanjutan untuk mewujudkan pengembangan peserta didik yang berkualitas salah satu yang sudah dilakukan adalah dengan pengembangan 
pembuatan media pembelajaran mading sebagai penunjang strategi, dan memberikan wadah bagi siswa untuk mengembangkan kreasi khususnya dalam bidang menulis dan membaca, serta meyalurkan bakat yang dimiliki oleh siswa.

Ada beberapa saran dan masukan agar mading di madrasah menjadi lebih kreatif, inovatif, dan bermakna, yaitu:

1. Guru harus selalu memberikan dorongan motivasi kepada siswa untuk selalu membaca buku-buku.

2. Seluruh siswa/i dapat berpartisipasi dalam penulisan mading di MIM Medura

3. Pergantian isi dari mading dapat di rubah setiap 3 minggu sekali.

4. Tema mading dapat disesuaikan dengan tema-tema yang merujuk kepada nilainilai karakter keislaman.

\section{UCAPAN TERIMA KASIH}

Pada kesempatan ini, tim pengabdian kepada masyarakat menyampaikan terima kasih kepada:

1. Ir. Eko Muh Widodo, MT (Rektor Universitas Muhammadiyah Magelang), yang telah memberi kesempatan kepada tim Pengabdian Kemitraan Universitas (PKU) dalam program untuk memperoleh dana pengabdian ini.

2. Dr. Heni Setyowati, E.R, S.Kp.,M. Kes. (Ketua LP3M Universitas Muhammadiyah Magelang), yang telah meberikan fasilitas dan rekomendasi persetujuan proposal pengabdian masyarakat ini untuk mendapatkan dana dari Universitas Muhammadiyah Magelang.

3. Dr. Nurodin Usman, LC.,MA) Dekan Fakultas Agama Islam Universitas Muhammadiyah Magelang yang telah memberi Surat Tugas kepada tim untuk melaksanakan pengabdian masyarakat ini.

4. Ibu Asmawati Khamidah Nur, S.Pd.I (Kepala MI Muhammadiyah Meduro) yang telah memfasilitasi kegiatan: a. Sosialisasi tentang pentingnya menulis dan membaca, b. Pelatihan pengembangan majalah dinding yang berkualitas dan menarik, c. Praktik pembuatan majalah dinding d. Pendampingan dalam pembuatan majalah dinding.

\section{DAFTAR PUSTAKA}

Peraturan Menteri Pendidikan dan Kebudayaan Nomor 23 tahun 2015 tentang Gerakan literasi sekolah memperkuat gerakan penumbuhan budi pekerti.

Dewi, Ayu. 2013. Majalah Dinding sebagai Implementasi Kemampuan Menulis Cerpen Siswa yang Mengikuti Ektrakurikuler Jurnalistik di SMP N 4 Singaraja. Jurnal Pendidikan Bahasa dan Sastra Indonesia Undiksha, Volume 1, No 1, hlm.1-15

Muntaha, Ahmad. 2009. Mudah dan Menyenangkan Jurnalistik dan Produksi Media Sekolah. Yogyakarta: Global Pustaka Utama Bekerjasana dengan PP IPM dan KIARA Yogyakarta

Santoso, Hari. 2007. Majalah Dinding Sebagai Media untuk Meningkatkan Kemampuan Menulis dan Budaya Baca Siswa. Malang: UPT Perpustakaan Universitas Negeri Malang 